Print ISSN: 2288-4637 / Online ISSN 2288-4645

doi:10.13106/jafeb.2018.vol5.no2.81

\title{
The Effective Factors of Professional Learning : Study on Accounting Firms in Korea ${ }^{1}$
}

\author{
Youjung Song' ${ }^{2}$, Wonsup Chang ${ }^{3}$, Jihyun Chang ${ }^{4}$ \\ Received: April 15, 2018. Revised: April 21, 2018. Accepted: May 15, 2018.
}

\begin{abstract}
The purpose of this study is to substantiate the affecting factors of informal learning outcomes for professions in various dimensions of an individual and organization. In specific, the study analyzed the effects of learning motivation, job characteristics, and a supportive learning environment which have on task-related knowledge acquisition, adapting to organization and understanding contexts, relationship formation, and improving self-development-ability. The participants of the study were 261 professionals working at four major accounting firms in South Korea. Multiple regression models were applied step by step for analysis. In this study, the informal learning of professionals working at four major accounting firms is influenced by various factors of learning motivation, job characteristics, and a supportive learning environment. The detailed analysis results were as follows. Firstly, peer-support showed the most positive effect on task-related knowledge acquisition. Secondly, for adapting to organization and understanding contexts, task autonomy showed the greatest effect. Thirdly, peer-support was found to be the most important factor for relationship formation. Fourthly, for improving self-development ability, learning goal orientation showed to be the most important factor. The various factors facilitated the professional learning by empirical identification. The study presented practical implications for creating an effective informal learning support environment.
\end{abstract}

Keywords: Professional Learning, Learning Motivation, Job Characteristics, Supportive Learning Environment, Accounting Firm.

JEL Classification Code: C42, I21, L49, L84, M41.

\section{Introduction}

Professions are undergoing new changes in their meaning, role and way of working. With the development of intelligent information technologies such as big data and artificial intelligence, professions such as medical, legal, and accounting are becoming more replaceable (Korea Employment Information Service, 2016). The professional world is facing significant changes.

In order to enhance professionalism in a rapid changing environment, professionals are required develop themselves continuously. Schön (1983) argued that professional education separate from the field might no longer deal with

1 This paper was modified and developed from the unpublished thesis of the first author.

2 First Author, Master and supervisor of Learning and Development center, Samjong KPMG, Korea.

3 Professor, Yonsei University, Korea.

4 Corresponding Author, Ph.D., Researcher of the Institute for Educational Research of Yonsei University, Korea, and director of FMASSOCIATES Business Academy, Korea.

E-mail: jchang0305@gmail.com actual problems due to different variables. Hence the professional education should transform into field-oriented education providing hands-on experience to allow professionals to reflect on such experiences. Cheetham and Chivers (2001), who identified professional learning methods, also found that professional learning might be achieved more effectively through observing, experiencing and reflecting in a practical context. Similarly studies on professional learning emphasize education at workplace, mainly through informal learning where exposure to work and learning simultaneously (Marsick, 2009). In addition, informal learning is considered as the most practical learning method to enhance the professionalism and selfdevelopment for professionals because the nature of the professional knowledge can be acquired effectively (Eraut, 2004).

Informal learning is an unstructured, unplanned learning based on learner-experience, including incidental forms (Marsick \& Watkins, 2001). Unlike traditional instructorcentered formal education, informal learning occurs in a learner-centered form involved in daily action, conversation, problem solving and projects at workplace. According to Marsick (2009), informal learning enables learners to learn and apply an organizational context, acquire work related 
problem-solving skills and transfer those into practice quickly.

It is important to note that, in the context of workplace learning, the informal learning is influenced by various factors such as personal characteristics, job characteristics, and organizational environment characteristics (Ellinger, 2005; Marsick \& Watkins, 2001; Sambrook \& Stewart, 2000). In other words, informal learning is determined by various factors of individual, job, and organizational dimensions. It is therefore necessary to examine factors at multiple dimensions while promoting informal learning.

Even though there are various views regarding factors affecting informal learning, motivation has to be considered as the most important aspect of the learning as it is an essential requirement for learners to stimulate their willingness to learn (Zusho, Pintrich, \& Coppola, 2003). Individual's learning motivation increases interests in learning which consequently leads to voluntary participation in learning activities (Lohman, 2005). In addition, informal learning takes place in daily work activities (Marsick, 2009). Thus, the job characteristics performed by an individual may also affect such learning. In fact, it is proven that the job characteristics have a significant influence on informal learning (Doornbos, Simons, \& Denessen, 2008; Ellström, 2001; Sklue, 2004). Although there are a number of variables which may influence on the effectiveness of training, development efforts and environmental support including learning support and systems at an organization, is important to promote individual learning activities (Tracey \& Tews, 2005). Organizations can facilitate informal learning for their employees through providing an institutionally supportive environment. Expanding opportunities for participation in learning and ease of access to learning resources can be good options. In addition, since informal learning occurs in daily interactions within members of organization, the depth of learning is depending on whether the workplace has a sharing field or not (Billett, 2000; Boud \& Middleton, 2003; Ellinger, 2005; Eraut, 2004; Hojabri, Eftekhar, Sharifi, \& Hatamian, 2014; Zahm, Veach, Martyr, \& Leroy, 2016).

This study empirically analyzed the effects of learning motivation, job characteristics, and supportive learning environment on informal learning for professionals working at a major accounting corporation in Korea. Since the major accounting firms provide professional services related to tax, finance, corporate management, etc., they require experts who can carry out those specialized tasks. Therefore, it is crucial to have expertise and service attitudes of professionals who are core internal customers of accounting firms (Lindsay, 2016). In order for them to learn and acquire such required knowledge, professionalism, and attitudes, it is necessary to consider different factors that can stimulate individual learning. In particular, the current study examined the factors effecting on acquiring task-related knowledge, adapting to organization, understanding context, acquisition of relationship formation, and improving self-development ability. By clarifying the factors that can increase the outcomes of informal learning, this study intended to draw implications to create an effective learning support environment.

\section{Literature Review}

\subsection{Professional workplace learning}

A Profession is an organization or a group that has exclusive autonomy based on long education, training, and experience as an occupation that performs specialized knowledge tasks that are not accessible unless training and experience is gained (Freidson, 2001). A profession is a social and collective concept distinguished from just being an occupation and has different attributes from an expert as an individual. This is an occupational group with higher ethics and social rights, while enjoying autonomy of work and being granted social rights and professional monopoly based on a higher academic knowledge system than other occupational groups.

In general, knowledge-based professions require more self-development in terms of education, learning, and growth than for other occupations. The judgment and the knowledge system required in the professional workplace are obtained through the experience and reflection from tacit behaviors of daily life (Schön, 1983). Because of these characteristics, professional learning needs to be approached through observation, experience, and reflection in the context of practice rather than formal education (Cheetham \& Chivers, 2001). In addition, most professionals tend to participate in learning when they consider that the time they take to engage in learning is more valuable than the amount of time they face (Woods \& Marsden, 2009). Formal education of unilateral knowledge transfer can face doubt and defensive attitude towards learning efficacy. Most of all, informal learning is more effective than formal education, which is separate from the field, in order to deal with the practical problems of various situations in the professional workplace (Lindsay, 2016; Webster-Wright, 2009).

\subsection{Learning motivation and informal learning}

Learning motivation, an important concept in educational psychology, is considered as a sub-concept of motivation. It is the most important factor among the psychological 
characteristics that induce learners' learning activities (Vallerand, Pelletier, Blais, Briere, Senecal, \& Vallieres, 1992). This is the internal and external condition for the learners to prepare for specific learning or to participate in a series of learning. Therefore, learning motivation can be defined as an internal state or process that generates individual learning behaviors and determines the direction and intensity of behaviors (Schunk, Meece, \& Pintrich,, 2012). Bandura (1991) suggested that motivation in learning situations is a source of learner's voluntary behavior and endeavoring to solve problems.

Informal learning is learning that takes place in a context associated with work in the workplace. Therefore, it is not a formal learning, but a self-directed learning that makes learners perform learning for themselves and find how to do so (Rowden, 2002). Marsick and Watkins (2001) argued that informal learning is facilitated by individual choice and will, emphasizing individual intention. The process of informal learning is not determined by the organization, but is a natural learning opportunity in work activities (Ellinger, 2005) that can control and guide learning for oneself (Eraut, 2004). In this way, informal learning is promoted according to learners' will and control, thus, learning motivation is an important factor that can directly affect informal learning (Kremer, 2006; Lohman, 2005). Therefore, the following hypothesis can be suggested.

$<$ Hypothesis $1>$ Learning motivation will have a positive effect on informal learning.

As informal learning takes place continuously at the workplace rather than at a specific point in time, it should be considered together with how to promote the motivation to continue and strengthen the learning as well as the motivation to participate learning (Pintrich, Smith, Garcia, \& McKeachie, 1993). The theory that emerges from this viewpoint is expectancy value theory. It is the most common theory to explain the motivation of the members in the organizational behavior field, and include context variables (Pintrich et al., 1993).

Pintrich et al. (1993)'s Motivated Strategies for Learning Questionnaire (MSLQ) is a representative learning motivation measurement tool developed on context-specific motivation scale based on expectancy value theory. In this measure, value components include intrinsic goal orientation, extrinsic goal orientation, and task value. Expectancy components include control belief, self-efficacy for learning and performance. Although MSLQ originally classified goal orientation into intrinsic and extrinsic goal orientation, research related to adult learners classified goal orientation into performance and learning goal orientation (Button, Mathieu, \& Zajac, 1996; Zusho, Pintrich, \& Coppola, 2003).
The meanings of each factor in learning motivation are as follows. First, performance goal orientation means a tendency to seek favorable evaluations of their abilities and avoid negative outcomes (Button et al., 1996). Second, learning goal orientation is a tendency to try to challenge new things and to focus on developing their abilities through learning (Schunk et al., 2012). Third, task value is the perception of the interest, importance, and usefulness of learners' content (Pintrich et al., 1993). Fourth, Self-efficacy for learning means self-efficacy on learning outcomes. This is a belief in the learners' ability to successfully perform their learning and reach their expectations (Bandura, 1991).

A number of previous studies that attempted to identify learning motivation factors related to informal learning have shown that learning motivation factors that affect informal learning may vary among learners. Kremer (2006), who examined the participation factors and interferences of informal learning for law firm employees, classified learning motivation into six categories: social relationship, learning orientation, external expectation, community contribution, skill acquisition, and growth. Among them, Kremer (2006) found that skills acquisition, learning orientation, and growth were the more important factors in informal learning in order. Moon and $\mathrm{Na}$ (2011) who analyzed the relationship of learning motivation with informal learning presented the results that learning goal orientation is more effective motivator for informal learning than performance goal orientation. In this way, the motivational factors of learning appears to be different in the previous studies analyzing different learner groups. Hence, it is necessary to explore the motivational factors that are important for the informal learning of the professionals.

\subsection{Job characteristics and informal learning}

Informal learning takes place in everyday work activities (Marsick, 2009). In other words, work and learning are inseparable and experience through work process leads to learning. Therefore, the type of task performed and the experience gained through the task are highly relevant to contents and results of the learning. In other words, the characteristics of the job being performed can determine the contents and outcomes of the particular learning.

From the previous studies, job characteristics were found to be highly related to informal learning. Lohman (2005), who reviewed informal learning for teachers and HRD staff, showed that there were differences in the informal learning outcomes of the participants performing other tasks. In his study, it was found that teachers primarily engaged in informal learning through interaction, and HRD staff mainly engaged in informal learning through personal reflection. Doornbos et al. (2008), who studied job characteristics as 
related variables of informal learning, found that informal learning was enhanced as the task diversity increases. Ellström (2001) also found that job diversity affects organizational learning facilitation. These findings show that task variation, which requires new and challenging tasks, stimulates informal learning. Task autonomy also appears to influence informal learning outcomes. Since task autonomy means freely determining the process and method of performing a task (Ellström, 2001), it is more likely for learners to choose and try new work processes and methods rather than working in a given manual. In addition, the opportunity of learning in such a process can also be enhanced. However, Doornbos et al. (2008) and Kwakman (2003), who analyzed secondary school teachers, showed that task autonomy had no significant effect on informal learning. There were also studies examining the effect of work pressure on informal learning. According to the study of Kwakman (2003), work pressure had a significant effect on cooperative learning in the workplace and did not show any significant effect on personal learning and teaching activities. Work pressure, which refers to the degree to which workers perceive their work must be completed quickly and accurately, has been found to be an impediment to learning and has a positive effect on relationships (Doornbos et al., 2008).

In summary, task variation, task autonomy, and work pressure may be considered as factors that can facilitate informal learning. Therefore, the following hypothesis can be suggested.

$<$ Hypothesis 2> Job characteristics will promote informal learning.

However, previous researches have presented somewhat inconsistent results, such as different analytical results depending on the different jobs analyzed, and effective or ineffective effects on different informal learning outcomes. Thus, an exploratory study is needed to investigate which job characteristics are more effective in promoting informal learning of professional workers.

\subsection{Supportive learning environment and informal learning}

Workers' behavior in the workplace is not determined solely by individual characteristics, but by interactions with the workplace context. Support from work colleagues such as supervisors and peers helps individuals at work as critical psychological resources (Ahmed, Majid, \& Zin, 2016). According to the study conducted by Tracey and Tews (2005), a co-operative environment or setting plays an important role in determining the effectiveness of training and development. Learning in the workplace is closely related to the humane, physical, social, and psychological contexts of norms, customs, bosses and colleagues of the organization to which these belong (Tracey \& Tews, 2005). The supportive learning environment of the organization provides support for diverse learning activities in the workplace, providing the institutional support and resources needed to enhance the learning effectiveness of the employees as well as opportunities for legal participation (Parveen, Ullah, Salam, \& Zakir, 2014). Also, if employees' perception on organizational support remains high, attitudes and behaviors of employees shows positivity and this benefits an organization (Kang \& Hwang, 2014). In general, people have positive attitude when their work matches their needs and interests, when working conditions are satisfactory and when the employees like their colleagues (Venkatesh \& Sharma, 2015).

Organizational contextual environments such as supportive learning environments have a great impact on informal learning (Sambrook \& Stewart, 2000). First, it is very important to systematically guarantee the learning environment so that members can conduct their own learning. Organizational support includes rewards for learning as an organizational culture, policy, or system that can facilitate and actively support the learning activities of organizational members (Tracey, Tannenbaum, \& Kavanagh, 1995). In addition, unlike formal education which takes place at a specific place such as a lecture hall separated from the workplace, informal learning occurs mostly in the workplace. Since informal learning is frequently performed through conversations with supervisors and colleagues, observation on them, contact with customers and in meetings, routine interaction with others has been known to be an important method of informal learning (Boud \& Middleton, 2003. Zahm et al., 2016). Among them, managerial support refers to the support or feedback from a supervisor or manager that helps to apply the knowledge, skills, and attitudes resulting from learning in the workplace (Holton et al., 1997). In applying the learning content to work, managerial support includes efforts to strengthen the supervisor's positive interest or reinforcement, and to assist setting specific goals. Peer-support refers to support and feedback received from colleagues around the workplace to utilize the knowledge, skills, and attitudes learned in the workplace in practice (Holton et al., 1997). Peer is the closest criterion to change behavior in the workplace. Peer-support has emotional aspect as well as informational aspect.

Numerous empirical studies have supported the importance of a supportive learning environment for promoting informal learning. The study of Enos, Kehrhahn, and Bell (2003) found that the organizational support, 
managerial support, and peer-support have positive effects on informal learning while reviewing informal learning of workers in large companies. Thus, the following hypothesis can be presented.

$<$ Hypothesis 3> The supportive learning environment will encourage informal learning.

\section{Methodology}

\subsection{Research Model}

Based on literature review, the research model designed to examine the factors promoting the informal learning of professional workers is shown in <figure 1>.

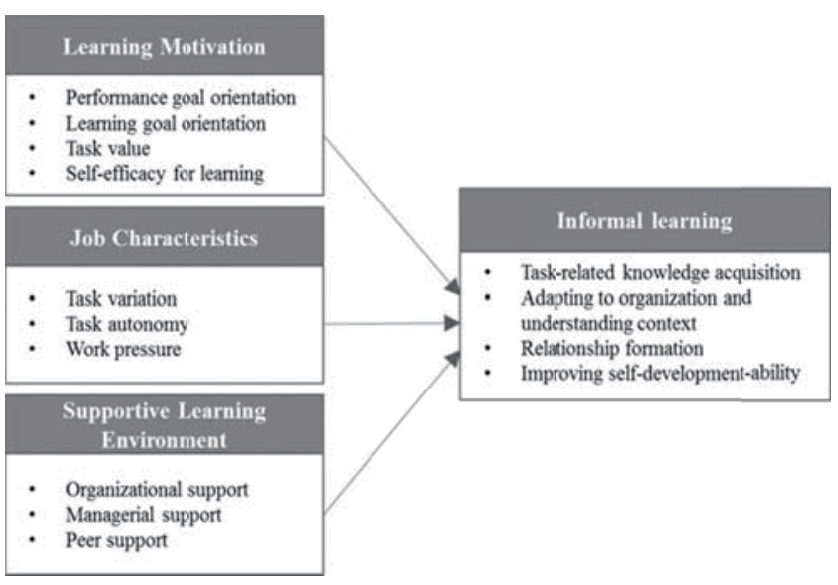

Figure 1. Research Model

\subsection{Participants}

The participants of the current study are the professionals of domestic large accounting corporations. This study scrutinizes the data of professionals who work for the 'large accounting firm,' a category set by the Financial Supervisory Service (Quality Control Manual for Accounting Firms, 2012). This study applied the convenience sampling method from March 22 to 31, 2017, but data were collected with considering the occupation and job distribution of the four large accounting firms. An online survey was conducted through social network service and e-mail, and 261 collected data were analyzed.

The general characteristics of the subject analysis are as follows. Of the 261 collected data, S Corporation accounted for $57.9 \%$, P Corporation for $17.2 \%$, A Corporation for $12.3 \%$, and $\mathrm{H}$ Corporation for $12.6 \%$. Response from male was $63.9 \%$ of the total. All graduates of the four-year College or above were $76.2 \%, 18.4 \%$ for master, and $5.4 \%$ for doctoral degree. Among the job types, $40.6 \%$ belongs to audit, $8.1 \%$ works for tax, $16.1 \%$ are from financial services, and $35.2 \%$ belongs to consulting. The portion of staff rank was $23.4 \%$, senior $23.7 \%$, supervising senior $13.8 \%$, manager $16.9 \%$, senior manager $10 \%$, director $8.4 \%$ and partner $3.8 \%$.

\subsection{Measures}

\subsubsection{Learning motivation}

Learning motivation, as a sub-factor to Motivation, becomes both internal and external factors that allow learners to prepare and participate in certain learning processes (Schunk et al., 2012). This study divided learning motivation factors into performance goal orientation, learning goal orientation, task value and self-efficacy for learning. For measuring performance goal orientation and learning goal orientation, a tool developed by Button et al. (1996) was used. Button et al. (1996) developed the tool consisting of 10 items with 7 point scale based on the motivational theory's two types of goal which had been defined by Dweck and her colleagues (Dewck, 1989; Heyman \& Dweck, 1992). Task value and self-efficacy, were measured by 'A Manual for the Use of the Motivated Strategies for Learning Questionnaire (MSLQ)', a tool developed by Pintrich et al. (1991). Task value was evaluated by 6 items and self-efficacy for learning had 8 items, with 7-point scale. Moon and $\mathrm{Na}$ (2011) translated it in Korean and modified it to 5-point Likert scale. Through series of applications to different enterprises in Korea, the modified had been validated (Moon \& $\mathrm{Na}, 2011$ ).

Learning goal orientation means a tendency to concentrate on developing an individual's ability, and there were six questions. Task value was perceived by the learners about the interest, importance and usefulness of learning contents. Self-efficacy for learning refers to an assessment of self-efficacy that learners will be able to successfully perform-learning, and there were seven questions. Participants responded to these questions with a five point Likert scale ranging from 'not at all' to 'very much'.

This study used exploratory factor analysis to validate the learning motivation variable. Principal component analysis was used for factor extraction and Varimax was used for factor rotation. As a result of factor analysis, all the four factors of learning motivation showed commonality more than .4 , and the factors with eigenvalue of 1 or more were extracted as four factors. The total variance explained for the four motivational factors was $59.5 \%$. The Cronbach's $\alpha$ reliability, which measures the internal consistency of the performance goal items, was .794. The alpha coefficient reliability of the learning goal orientation, task value, and 
self-efficacy for learning items were .842, .860, and .887, respectively. The results of descriptive statistics for learning motivation are shown in <Table 1>

\subsubsection{Job characteristics}

Job characteristics mean that individuals perceive meaning, sense of responsibility, and the results of their tasks by performing their jobs (Hackman \& Oldham, 1976). Job characteristics are task variation, task autonomy, and work pressure. We used the measurement tool of Moon and $\mathrm{Na}$ (2011), which verified the validity of Doornbos et al. (2008)'s Learning from Police Work Questionnaire (LPWQ). Task variation is to recognize that new and challenging tasks are assigned. Task autonomy is to recognize that the process of performing a given task can be controlled by itself, and work pressure is to recognize that tasks must be completed on time (Doornbos et al., 2008). The number of items for task variation, task autonomy, and work pressure were 13,6 , and 3 , respectively, and 5-point Likert scale was applied.

Principal component analysis was used for factor extraction, and Varimax, a square rotation method, was used for factor rotation. The commonality of each of the three factors was found to be over 4 , and the factor with more than one eigenvalue was extracted as three factors. The reliabilities of task variation, task autonomy, and work pressure were $.857, .890$, and .731 , respectively. The results of descriptive statistics of job characteristics are also shown in $\langle$ Table 1$\rangle$.

\subsubsection{Supportive learning environment}

The supportive learning environment consists of three sub-factors: organizational support, managerial support, and peer-support. Organizational support includes rewards for learning as an organizational culture, policy or system that can encourage the participation of organizational members in learning activities. Managerial support means that supervisors or managers encourage learning activities, providing information related to learning activities, and coordinating work schedules for learning. Peer support is the support from colleagues who can apply the learning to the work situation. In this study, organizational support and managerial support were measured based on the items of Choi and Jacobs (2011), which were modified by translating the measurement tool developed by Tracey and Tews (2005) into Korean, and the 5 point Likert scale was applied for the measurement. Peer support is described by Feldman (1981) and Tracey et al. (1995) and Kang (2005) translated the concept into Korean and partially corrected it. Four items were used to measure organizational support, managerial support, and peer support, and also a five-point Likert scale was used.

Principal component analysis was used for factor extraction and Varimax for factor rotation. The commonality of all the three factors was higher than .4, and the eigenvalue was extracted to be higher than 1. The three extracted factors accounted for $67 \%$ of the total input variable. The alpha coefficient reliabilities of organizational support, managerial support, and peer support were $.819, .715$, and .851 respectively. The results of the descriptive statistics for the supportive learning environment are also shown in $\langle$ Table 1$\rangle$.

\subsubsection{Informal learning}

In the previous study, Moon and $\mathrm{Na}$ (2011) identified the outcomes of informal learning through the analysis of previous research and conceptualized informal learning based on it. Then, it examined validity and reliability through two preliminary surveys. The items that best describe the meanings of the job offer were extracted and the final measurement tool was used. The questionnaire items were composed of 19 items that corresponded to four sub-factors including task-related knowledge acquisition, adapting to organization and understanding context, relationship formation and improving self-development ability. 5-point Likert scale was also applied. The higher the score indicates the higher the achievement of learning outcomes. Taskrelated knowledge acquisition is the acquisition of new methods for existing tasks and acquiring knowledge of the changed tasks, adapting to organization and understanding context to acquire knowledge and skills necessary to understand context and effective adaptation. The degree of relationship formation is the degree to which they acquire the necessary methods to interact with others and strengthen their cooperation, and the capability to improve self-development ability through self-reflection (Moon \& $\mathrm{Na}$, 2011). Four items were used for task-related knowledge acquisition; five items for adapting to organization and understanding context, six items for relationship formation, and four items for improving self-development ability.

Principal component analysis was used for factor extraction and Varimax for factor rotation. As a result of the factor analysis, we removed one item that was differently bundled in the items of adapting to organization and understanding context. The commonality of the remaining 18 items was higher than 4 items had the factor of 1 or higher. The reliability values for task-related knowledge acquisition, adapting to organization and understanding context, relationship formation, and improving selfdevelopment ability came out to be $.805, .859, .841$, 
and .799 , respectively. The results of descriptive statistics on informal learning results are shown in $<$ Table $1>$.

\subsubsection{Control variables}

Finally, the personal variables included in the analysis were gender, education, job, and rank. The multi-collinearity problem of the explanatory variables included in the regression analysis had been examined in order to select the variables.

All control variables were converted into dummy variables. Male and female employees were classified as 'male $=1$ ' and 'female $=0$ ', respectively. The task types were generated into two dummy variables, financial services and consulting services, with reference to accounting audit and tax services. For categorizing individuals' positions, dummy variables for graduate staff, supervising senior, manager, senior manager, director and above were analyzed with senior being a reference group. The results of both descriptive and correlation analysis between all the variables are shown in $<$ Table 1>.

\subsection{Analytic strategy}

This study used SPSS 21.0 statistical package program for data analysis and conducted analysis through the following procedure. First, descriptive statistical analysis was performed to confirm the data characteristics of the subjects and the variables. Second, the exploratory factor analysis was conducted to verify the factor's validity of the variables. Then the reliability analysis was performed with Cronbach's a coefficient confirming the internal consistency between the items of each variable. Third, Pearson correlation analysis was performed to confirm the correlation between variables, and the variables to be added to the regression model were selected through a stepwise review. Fourth, multiple regression analysis was applied to examine the relationship between various factors and informal learning.

As a result of correlation analysis, learning motivation and supportive learning environment sub-factors showed high correlation with each other. In addition, when regression analysis was conducted to these sub-factors the standard error increased as the number of factors being increased. In order to reduce the problem of multi-collinearity, the study examined the relative effect sizes by examining the change of explanatory power by adding the factors of learning motivation and supportive learning environment step by step. Analytical models were divided into two groups as model 1 and model 2 through 8 . Model 1 is a model with control variables and job characteristics. Models 2 through 5 are ones that add the factors of learning motivation step by step, and models 6 through 8 are models that add the factors of supportive learning environment step by step.

Table 1. Descriptive Statistics and Correlation

\begin{tabular}{|c|c|c|c|c|c|c|c|c|c|c|c|c|c|c|c|c|c|c|c|c|c|c|c|c|}
\hline & Mean & SD & 1 & 2 & 3 & 4 & 5 & 6 & 7 & 8 & 9 & 10 & 11 & 12 & 13 & 14 & 15 & 16 & 17 & 18 & 19 & 20 & 21 & 22 \\
\hline $\begin{array}{l}\text { 1. Task-related knowledge } \\
\text { acquisition }\end{array}$ & 3.843 & .544 & 1 & & & & & & & & & & & & & & & & & & & & & \\
\hline $\begin{array}{l}\text { 2. Adapting to organization and } \\
\text { understanding contexts }\end{array}$ & 3.455 & .829 & $.461^{\star \star}$ & 1 & & & & & & & & & & & & & & & & & & & & \\
\hline 3. Relationship formation & 3.803 & .626 & $.531 * \star$ & $603^{* \star}$ & 1 & & & & & & & & & & & & & & & & & & & \\
\hline $\begin{array}{l}\text { 4. Self-development ability } \\
\text { improvement }\end{array}$ & 3.905 & .676 & $.392^{* *}$ & $456 * \star$ & $.511^{* \star}$ & 1 & & & & & & & & & & & & & & & & & & \\
\hline 5. Performance goal orientation & 3.940 & .642 & .106 & -.025 & .066 & .054 & 1 & & & & & & & & & & & & & & & & & \\
\hline 6. Learning goal orientation & 4.102 & .588 & $317^{* *}$ & $320 *$ & $317^{* *}$ & $398^{* *}$ & -.007 & 1 & & & & & & & & & & & & & & & & \\
\hline 7. Task value & 3.920 & .698 & $.340^{* *}$ & $303^{* *}$ & $332 * *$ & $303^{* *}$ & $262^{* *}$ & $407 * *$ & 1 & & & & & & & & & & & & & & & \\
\hline 8. Self-efficacy for learning & 3.891 & .583 & $248^{\star *}$ & $281^{* *}$ & $.355^{\star *}$ & $384^{* *}$ & $.130^{*}$ & $.598^{\star *}$ & $.440^{* *}$ & 1 & & & & & & & & & & & & & & \\
\hline 9. Task variation & 3.700 & .814 & $.138^{*}$ & $.151^{*}$ & $.126^{*}$ & $298^{\star *}$ & .066 & $317^{* *}$ & $218^{* *}$ & $.325^{* *}$ & 1 & & & & & & & & & & & & & \\
\hline 10. Task autonomy & 3.126 & .920 & .109 & $.432^{* \star}$ & $.223^{* *}$ & $214^{* \star}$ & $-.127^{*}$ & $.131^{*}$ & $.169^{* \star}$ & $.274^{* \star}$ & $.145^{\star}$ & 1 & & & & & & & & & & & & \\
\hline 11. Work pressure & 3.817 & .778 & .026 & -.043 & .024 & .055 & .078 & $.135^{*}$ & .073 & $.141^{*}$ & $213^{* \times}$ & -.120 & 1 & & & & & & & & & & & \\
\hline 12. Organizational support & 3.018 & .858 & $.196^{\star *}$ & $388^{* *}$ & $230^{* *}$ & $.187^{* *}$ & $.180^{\star \star}$ & .094 & $291^{* *}$ & .085 & $188^{\star *}$ & $209^{\star *}$ & .003 & 1 & & & & & & & & & & \\
\hline 13. Managerial support & 2.841 & .753 & .106 & $310^{* *}$ & $.187^{* \star *}$ & $.127^{*}$ & $.131^{*}$ & .001 & $203^{\star \star}$ & -.008 & .050 & $239 * \star$ & $-.140^{*}$ & $631^{\star \star}$ & 1 & & & & & & & & & \\
\hline 14. Peer support & 3.654 & .803 & $.414^{\star \star *}$ & $185^{\star \star}$ & $.328 * \star$ & $.185^{\star \star}$ & $.236^{\star \star}$ & .087 & $255^{\star \star}$ & .058 & $186^{* \star}$ & .024 & .058 & $461^{\star \star}$ & $.404^{\star *}$ & 1 & & & & & & & & \\
\hline 15. Gender (male=1) & .724 & .448 & -.059 & .008 & .030 & $164^{\star \star}$ & .109 & .072 & .022 & .042 & .115 & -.001 & .017 & .038 & .012 & -.066 & 1 & & & & & & & \\
\hline 16. Education & .237 & .426 & .028 & .115 & .096 & -.055 & $-163^{\star \star}$ & .066 & -.043 & .034 & -.018 & $.186^{\star \star}$ & -.089 & .022 & -.014 & $-183^{\star k}$ & -.058 & 1 & & & & & & \\
\hline 17. Staff & .233 & .424 & -.041 & $-172^{\star \star}$ & -.104 & -.073 & $.167^{\star \star}$ & -.099 & .027 & $-.146^{*}$ & $-250^{* x}$ & $-305^{\star \star *}$ & .087 & .004 & .014 & .026 & -.024 & $-223^{\star x+}$ & 1 & & & & & \\
\hline 18. Supervising senior & .137 & .345 & .054 & -.015 & .073 & .073 & -.041 & .006 & .018 & .031 & .103 & -.049 & -.025 & .034 & -.015 & $.131^{*}$ & $-201^{* *}$ & -.119 & $-221^{* \star}$ & 1 & & & & \\
\hline 19. Manager & .168 & .375 & .078 & .043 & $.123^{*}$ & .014 & -.088 & $.159 * \star x$ & .022 & $.182^{* *}$ & .072 & $.148^{*}$ & .027 & -.108 & -.061 & .015 & .049 & .013 & $-249^{* *}$ & $-180^{* *}$ & 1 & & & \\
\hline 20. Senior manager and above & .221 & .417 & -.037 & $179^{* \star}$ & .085 & .109 & -.027 & .040 & -.012 & .044 & .033 & $.345^{\star \star}$ & .019 & .096 & .055 & -.111 & $.144^{*}$ & $308^{\star \star x}$ & $-295^{* *}$ & $-214^{* *}$ & $-241^{* *}$ & 1 & & \\
\hline 21. Financial services & .160 & .368 & -.023 & -.023 & .029 & .000 & $-.149^{*}$ & .015 & -.118 & -.003 & .107 & -.110 & -.054 & -.055 & -.036 & -.019 & -.033 & .025 & -.045 & .067 & .081 & -.008 & 1 & \\
\hline 22. Consulting & .352 & .479 & .053 & $.137^{\star}$ & .091 & .044 & -.071 & .117 & .070 & .105 & .087 & $264^{* *}$ & -.047 & .005 & $\mid-.004$ & -.057 & -.083 & $285^{\star *}$ & $-294^{* *}$ & $.147^{*}$ & .053 & .049 & $-323^{\text {tx }}$ & 1 \\
\hline
\end{tabular}

${ }^{*} p<.05,{ }^{* *} p<.0$ 


\section{Results}

\subsection{The effects of learning motivation, job characteristics, supportive learning environment on task-related knowledge acquisition}

$<$ Table 2> shows the results of the analysis of the effects of learning motivation, job characteristics, and supportive learning environment on task-related knowledge acquisition. As previously mentioned, model 1 was for control and job characteristics variables, and model 2 to model 5 were to add learning motivation factors one by one. Model 6 through model 8 were designed to analyze the effects of a supportive learning environment factors. This study, through step-bystep analyses, was able to compare the relative effects of independent variables on task-related knowledge acquisition, which is a dependent variable, by comprehensively examining the standardized regression coefficient in the analysis models and the change in the $\mathrm{R}^{2}$ of the analyses models. As results of the analysis, peer-support (15.4\%), task value (9.2\%), and learning goal orientation $(7.8 \%)$ showed a great influence on task-related knowledge acquisition. These results confirm that organizational peer-support is the most important for taskrelated knowledge acquisition through informal learning; and that task value and learning goal orientation are also important learning motivation factors. Self-efficacy for learning (3.6\%), organizational support $(2.8 \%)$ and performance goal orientation $(1.5 \%)$ showed statistically significant positive effects, but the analysis models themselves was not statistically significant. Job characteristics did not show any statistically significant effect, so it was not possible to confirm the relationship with task-related knowledge acquisition.

\subsection{The effects of learning motivation, job characteristics, supportive learning environment on adapting organization and understanding context}

$<$ Table $3>$ shows the results of the analysis of adapting to organization and understanding context. As a result, all the motivation factors except performance goal orientation, all factors of supportive learning environment, and task autonomy of job characteristics showed a statistically significant positive effect on adapting to organization and understanding context. In order to analyze the effects of learning motivation, the study examined the changes of $\mathrm{R}^{2}$ from models 2 to model 5 , and showed relative importance in the following order; learning goal orientation (6.6\%), task value $(5.4 \%)$, and learning self-efficacy for learning $(2.5 \%)$. Models 6 to 8 were to analyze the effects of supportive learning environments, which showed relative effectiveness of organizational support $(8.9 \%)$, managerial support $(4.7 \%)$ and peer-support (3.2\%). In addition, the study found that task autonomy had the strongest influence on adapting to organization and understanding context, as a result of comparing the standardized regression coefficient $\beta$ s of job characteristics in each model.

\subsection{The effects of learning motivation, job characteristics, supportive learning environment on relationship formation}

$<$ Table 4> shows the results of the stepwise analysis on the relationship formation. As a result, all learning motivation factors except for performance goal orientation, all supportive learning environment factors, and task autonomy of job characteristics showed a statistically significant positive effect on the relationship formation. Comparing the $\mathrm{R}^{2}$ changes from models 2 to model 5 , there were relatively large effects in order of task value $(8.7 \%)$, self-efficacy for learning $(7.4 \%)$ and learning goal orientation $(6.4 \%)$. In addition, it was found from models 6 to model 8 that peersupport (10.6\%), organizational support (3.6\%) and managerial support $(2.5 \%)$ were influential on relationship formation. Also, task autonomy had a positive effect on the relationship formation but the standardized regression coefficient for comparing the relative effect sizes with other variables showed that there was relatively the lowest effect among the effective variables.

\subsection{The effects of learning motivation, job characteristics, supportive learning environment on improving self-development ability}

$<$ Table 5> shows the results of the analysis on improving self-development-ability. The results of the analysis presented that all learning motivation factors except performance goal orientation had statistically significant positive effects on improving self-development ability. Peersupport in the supportive learning environment, and task variation and task autonomy in the job characteristics had also statistically significant positive effects on improving selfdevelopment ability. This study found from $\mathrm{R}^{2}$ changes that learning goal orientation $(9.5 \%)$ had the greatest influence, followed by self-efficacy for learning (7.3\%) and task value (4.6\%). Job characteristics showed relatively large effect in task variation and task autonomy through standardized regression coefficients. Peer-support was also found to be an effective factor in supportive learning environment, but peer-support $(1.6 \%)$ was found to have the least impact on improving self-development ability. In sum, it was found that learning motivation corresponds to learning goal orientation, self-efficacy for learning, and task value was most important for improving self-development ability, and job characteristics 
of task variation and task autonomy were also important. Although peer-support of supportive learning environment factors showed positive effects, it showed relatively the weakest effect on improving self-development ability.

Table 2. Multiple regression analysis for task-related knowledge acquisition

\begin{tabular}{|c|c|c|c|c|c|c|c|c|c|c|c|c|c|c|c|c|c|c|c|c|c|c|c|c|}
\hline & \multicolumn{3}{|c|}{ Model 1} & \multicolumn{3}{|c|}{ Model 2} & \multicolumn{3}{|c|}{ Model 3} & \multicolumn{3}{|c|}{ Model 4} & \multicolumn{3}{|c|}{ Model 5} & \multicolumn{3}{|c|}{ Model 6} & \multicolumn{3}{|c|}{ Model 7} & \multicolumn{3}{|c|}{ Model 8} \\
\hline & B & SE & $\beta$ & B & SE & $\beta$ & B & SE & $\beta$ & B & SE & $\beta$ & B & SE & $\beta$ & B & SE & $\beta$ & B & SE & $\beta$ & B & SE & $\beta$ \\
\hline Intercept & $3.329^{*+1}$ & .261 & & $2.918^{\star \star \star}$ & .332 & & $2.542^{\star \star \star x}$ & .302 & & $2.661^{\text {*N }}$ & $x .280$ & & $2.868^{\star \star \star}$ & $\star .296$ & & $3.142^{\star \star \star \alpha}$ & $x .266$ & & $3.166^{\text {*内 }}$ & 284 & & $2.513^{\star \star x+k}$ & 267 & \\
\hline Gender (male $=1$ ) & -.074 & .079 & -.061 & -.085 & .079 & -.070 & -.089 & $.076-$ & -073 & -.075 & .075 & -.061 & -.078 & .078 & \begin{tabular}{|l|}
-.064 \\
\end{tabular} & -.079 & .078 & \begin{tabular}{|c|}
-065 \\
\end{tabular} & -.074 & .079 & -.061 & -.034 & 073 & -.02 \\
\hline $\begin{array}{c}\text { Education (master's degree } \\
\text { and above }=1 \text { ) }\end{array}$ & .051 & .090 & .040 & .070 & .089 & .055 & .032 & .086 & .025 & .063 & .085 & .049 & . 048 & .088 & .037 & .044 & .088 & .035 & .055 & 089 & .043 & .123 & .083 & .096 \\
\hline Staff & .057 & 105 & .044 & .033 & .105 & \begin{tabular}{|c|}
.026 \\
\end{tabular} & .023 & .101. & .018 & .001 & .100 & .001 & .046 & .103 & \begin{tabular}{|l|}
.036 \\
\end{tabular} & .035 & .104 & \begin{tabular}{|l|}
.027 \\
\end{tabular} & .049 & .105 & .038 & .025 & .096 & .020 \\
\hline Supervising senior & .089 & .118 & .056 & .088 & \begin{tabular}{|c|}
.117 \\
\end{tabular} & .056 & .067 & .113. & .043 & .070 & .112 & .044 & .069 & .116 & \begin{tabular}{|l|}
.044 \\
\end{tabular} & .074 & .116 & \begin{tabular}{|l|}
.047 \\
\end{tabular} & .091 & .118 & .057 & .018 & .109 & .011 \\
\hline Manager & .104 & $\mid .111$ & .071 & .106 & .111 & .073 & .031 & .108 . & .022 & .093 & .106 & .064 & .059 & .110 & \begin{tabular}{|l|}
.041 \\
\end{tabular} & .132 & .110 & \begin{tabular}{|l|}
.091 \\
\end{tabular} & .116 & .111 & .080 & .084 & .102 & .058 \\
\hline Senior manager and above & -.049 & .110 & -.037 & -.061 & .109 & -.046 & -.072 & .105- & -.055 & -.040 & .104 & -.031 & -.050 & .108 & \begin{tabular}{|l|}
-.038 \\
\end{tabular} & -.052 & .108 & $\mid-.040$ & -.044 & .110 & -.034 & -.030 & .101 & -.023 \\
\hline Financial services & -.060 & 102 & .041 & \begin{tabular}{c|c|}
.028 \\
\end{tabular} & .103 & -.019 & -.064 & $.098-$ & -.043 & -.005 & .098 & -.003 & -.058 & .100 & \begin{tabular}{|l|}
-039 \\
\end{tabular} & \begin{tabular}{|l|}
.043 \\
\end{tabular} & .101 & \begin{tabular}{|l|}
-029 \\
\end{tabular} & -.057 & .102 & -.038 & -020 & .094 & -.014 \\
\hline Consulting & -.013 & .085 & -.011 & $\begin{array}{l}.009 \\
\end{array}$ & .084 & -.008 & -.040 & $.082-$ & -.036 & -.016 & .081 & -.014 & \begin{tabular}{|l|}
.017 \\
\end{tabular} & .083 & -.015 & .002 & .084 & .002 & -.007 & .085 & -.006 & .024 & .078 & .021 \\
\hline Task variation & .091 & .046 & .136 & .080 & .046 & .120 & .034 & .046 . & .051 & .042 & .045 & .063 & .055 & .046 & \begin{tabular}{|l|}
.082 \\
\end{tabular} & .068 & .046 & .101 & .087 & .046 & .130 & .036 & .043 & .054 \\
\hline Task autonomy & .059 & .043 & .099 & .067 & .043 & \begin{tabular}{|c|}
.114 \\
\end{tabular} & .049 & .041 . & .083 & .025 & .042 & .043 & .029 & .043 & .050 & .035 & .043 & .059 & .044 & .044 & .074 & .043 & .040 & .073 \\
\hline Work pressure & .005 & .046 & .007 & .004 & .046 & .006 & -.012 & $.045-$ & -.017 & -.001 & .044 & -.002 & -.012 & .046 & -017 & .007 & .046 & .010 & .013 & .046 & .019 & .004 & .042 & .006 \\
\hline Performance goal orientation & & & & $.109^{*}$ & .055 & .129 & & & & & & & & & & & & & & & & & & \\
\hline Leaming goal orientation & & & & & & & $.279^{\star k \star}$ & .060 & .301 & & & & & & & & & & & & & & & \\
\hline Task value & & & & & & & & & & $.250^{\star \star \star *}$ & .049 & .321 & & & & & & & & & & & & \\
\hline Self-efficacy for learning & & & & & & & & & & & & & $.197^{\star \star}$ & .063 & .211 & & & & & & & & & \\
\hline Organizational support & & & & & & & & & & & & & & & & $.112^{\star \star}$ & .041 & .177 & & & & & & \\
\hline Managerial support & & & & & & & & & & & & & & & & & & & .066 & .047 & .092 & & & \\
\hline Peer support & & & & & & & & & & & & & & & & & & & & & & $.280^{*+\ldots}$ & .041 & .413 \\
\hline $\mathrm{R}^{2}$ & & .043 & & & .058 & & & 120 & & & .135 & & & .079 & & & .071 & & & .050 & & & .197 & \\
\hline Adjusted $\mathrm{R}^{2}$ & & .001 & & & .012 & & & 078 & & & .093 & & & .034 & & & .026 & & & .005 & & & .158 & \\
\hline$\Delta R^{2}$ & & & & & .015 & & & 078 & & & .092 & & & .036 & & & .028 & & & .008 & & & .154 & \\
\hline $\mathrm{F}$ & & 1.013 & & & .265 & & & $831^{* *}$ & & & $232^{\star \star \star}$ & & & 1.771 & & & 1.574 & & & 1.098 & & & $.071^{\star \star \star}$ & \\
\hline
\end{tabular}

${ }^{*} p<.05,{ }^{* *} p<.01,{ }^{* * *} p<.001$

B: unstandardized coefficient, SE: standard error, $\beta$ : standardized coefficient

Table 3. Multiple regression analysis for adapting to organization and understanding contexts

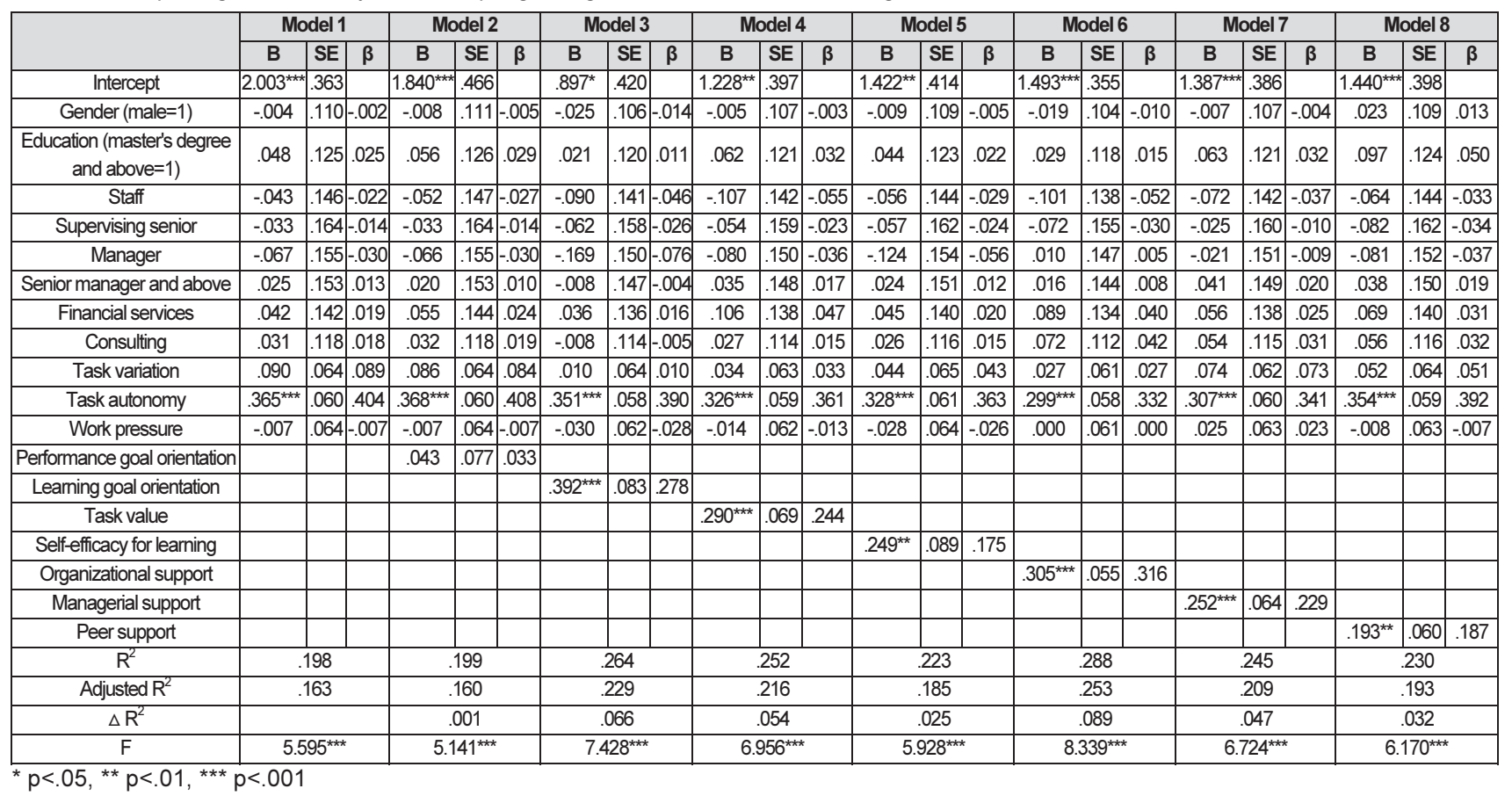

B: unstandardized coefficient, SE: standard error, $\beta$ : standardized coefficient 
Table 4. Multiple regression analysis for relationship formation

\begin{tabular}{|c|c|c|c|c|c|c|c|c|c|c|c|c|c|c|c|c|c|c|c|c|c|c|c|c|}
\hline & \multicolumn{3}{|c|}{ Model 1} & \multicolumn{3}{|c|}{ Model 2} & \multicolumn{3}{|c|}{ Model 3} & \multicolumn{3}{|c|}{ Model 4} & \multicolumn{3}{|c|}{ Model 5} & \multicolumn{3}{|c|}{ Model 6} & \multicolumn{3}{|c|}{ Model 7} & \multicolumn{3}{|c|}{ Model 8} \\
\hline & B & SE & $\beta$ & B & SE & $\beta$ & B & SE & $\beta$ & B & SE & $\beta$ & B & SE & $\beta$ & B & SE & $\beta$ & B & SE & $\beta$ & B & SE & $\beta$ \\
\hline Intercept & $2.882^{2+2}$ & . 292 & & $2.467^{\star \star}$ & .373 & & $2.060^{* \star \star x}$ & .340 & & $2.139^{* \star \hbar}$ & .314 & & $2.121^{\star \star \star \hbar}$ & .324 & & $2.639^{*+k x}$ & 297 & & $2.542^{\text {tkx }}$ & $x .316$ & & $2.103^{\star \star \star}$ & \begin{tabular}{|c|}
.307 \\
\end{tabular} & \\
\hline Gender (male=1) & .056 & $\mid .089$ & .040 & .044 & .089 & \begin{tabular}{|c|}
.032 \\
\end{tabular} & .040 & .086 & .029 & .055 & .085 & .039 & 048 & .085 & .035 & .049 & .087 & .035 & .054 & .088 & .039 & .093 & .084 & \begin{tabular}{|l|}
.067 \\
\end{tabular} \\
\hline $\begin{array}{c}\text { Education (master's degree } \\
\text { and above }=1 \text { ) }\end{array}$ & .104 & .100 & .071 & 123 & .100 & .084 & .084 & .097 & .057 & .117 & .096 & .080 & .098 & .096 & .067 & .095 & .099 & .065 & .112 & .099 & .077 & .172 & .095 & .117 \\
\hline Staff & .134 & .118 & .091 & .110 & .118 & .075 & .099 & .114 & .067 & .072 & .113 & .049 & .117 & .113 & .079 & .106 & .116 & \begin{tabular}{|l|}
.072 \\
\end{tabular} & .118 & .116 & .080 & .104 & .111 & .070 \\
\hline Supervising senior & $274^{*}$ & 132 & .151 & $273^{*}$ & .131 & .151 & .252 & .128 & \begin{tabular}{|l|}
.139 \\
\end{tabular} & $253^{*}$ & .126 & .140 & .242 & .127 & \begin{tabular}{|c|}
.134 \\
\end{tabular} & 255 & .130 & \begin{tabular}{|l|}
.141 \\
\end{tabular} & $.278^{*}$ & .130 & .153 & .206 & \begin{tabular}{|l|}
.125 \\
\end{tabular} & \begin{tabular}{|l|}
.114 \\
\end{tabular} \\
\hline Manager & $256^{*}$ & .125 & .153 & $.258^{*}$ & .124 & .155 & .180 & .122 & \begin{tabular}{|l|}
.108 \\
\end{tabular} & $.244^{*}$ & .119 & .146 & .182 & .121 & .109 & $.293^{*}$ & .123 & \begin{tabular}{|l|}
.175 \\
\end{tabular} & $.282^{\star}$ & .124 & .169 & $.237^{*}$ & \begin{tabular}{|l|}
.117 \\
\end{tabular} & \begin{tabular}{|l|}
.142 \\
\end{tabular} \\
\hline Senior manager and above & .130 & .123 & .086 & .118 & .123 & $\mid .078$ & .105 & .119 & .070 & .139 & .117 & .093 & .128 & .118 & .085 & .126 & .121 & .084 & .138 & .122 & .092 & .148 & $\mid .116$ & \begin{tabular}{|l|}
.098 \\
\end{tabular} \\
\hline Financial services & .053 & .114 & .031 & .086 & .115 & .051 & .050 & .110 & .029 & .115 & .110 & .068 & .057 & .110 & .034 & .076 & .112 & \begin{tabular}{|c|}
.045 \\
\end{tabular} & .061 & .113 & .036 & .092 & $\mid 108$ & \begin{tabular}{|l|}
.054 \\
\end{tabular} \\
\hline Consulting & .030 & .095 & .023 & .034 & .095 & .026 & .001 & .092 & .001 & .026 & .090 & .020 & .023 & .091 & .018 & .049 & .093 & \begin{tabular}{|l|l|}
.038 \\
\end{tabular} & .043 & .094 & .033 & .065 & .090 & .050 \\
\hline Task variation & .061 & .051 & .079 & .050 & .051 & .064 & .001 & .051 & .001 & .006 & .050 & .008 & .000 & .051 & .000 & .030 & .051 & .040 & .052 & .051 & .067 & .008 & .049 & \begin{tabular}{|l|}
.011 \\
\end{tabular} \\
\hline Task autonomy & $.124^{*}$ & $\mid .048$ & .182 & $.133^{\star \star}$ & .048 & $\mid .195$ & $.114^{*}$ & .047 & .168 & .087 & .047 & .127 & .076 & .047 & .111 & .093 & .048 & \begin{tabular}{|c|}
.137 \\
\end{tabular} & .093 & .049 & .136 & $.109^{*}$ & .046 & .160 \\
\hline Work pressure & .022 & .052 & \begin{tabular}{|c|}
.027 \\
\end{tabular} & .022 & .052 & .027 & .005 & .050 & $\mid .006$ & .016 & .049 & .019 & -.005 & .050 & -.006 & .025 & .051 & \begin{tabular}{|l|}
.031 \\
\end{tabular} & .040 & .052 & .049 & .021 & .049 & \begin{tabular}{|l|}
.027 \\
\end{tabular} \\
\hline Performance goal orientation & & & & .110 & .062 & .113 & & & & & & & & & & & & & & & & & & \\
\hline Leaming goal orientation & & & & & & & $.291^{\star k \star}$ & .067 & .274 & & & & & & & & & & & & & & & \\
\hline Task value & & & & & & & & & & $.278^{\star \star \star k}$ & $\mid .055$ & .311 & & & & & & & & & & & & \\
\hline Self-efficacy for leaming & & & & & & & & & & & & & $.325^{\star k \star}$ & .069 & .303 & & & & & & & & & \\
\hline Organizational support & & & & & & & & & & & & & & & & $.145^{\star k}$ & .046 & .199 & & & & & & \\
\hline Managerial support & & & & & & & & & & & & & & & & & & & $.139^{* *}$ & .052 & \begin{tabular}{|c|}
.167 \\
\end{tabular} & & & \\
\hline Peer support & & & & & & & & & & & & & & & & & & & & & & $.267^{\star \star \star}$ & $\mid 047$ & .343 \\
\hline $\mathrm{R}^{2}$ & & 090 & & & 101 & & & 154 & & & .177 & & & .164 & & & .125 & & & 115 & & & 196 & \\
\hline Adjusted $\mathrm{R}^{2}$ & & 050 & & & 058 & & & .113 & & & .137 & & & .124 & & & .083 & & & .072 & & & 158 & \\
\hline$\Delta R^{2}$ & & & & & .012 & & & .064 & & & .087 & & & .074 & & & .036 & & & .025 & & & 106 & \\
\hline $\mathrm{F}$ & & $237^{*}$ & & & $333^{* k}$ & & & $764^{4 \text { kt }}$ & & & $432^{\star \star \star}$ & & & $.063^{\star \star \star}$ & & & $2.965^{\star *}$ & & & $689^{* k}$ & & & $052^{2 k+}$ & \\
\hline
\end{tabular}

B: unstandardized coefficient, SE: standard error, $\beta$ : standardized coefficient

Table 5. Multiple regression analysis for self-development ability improvement

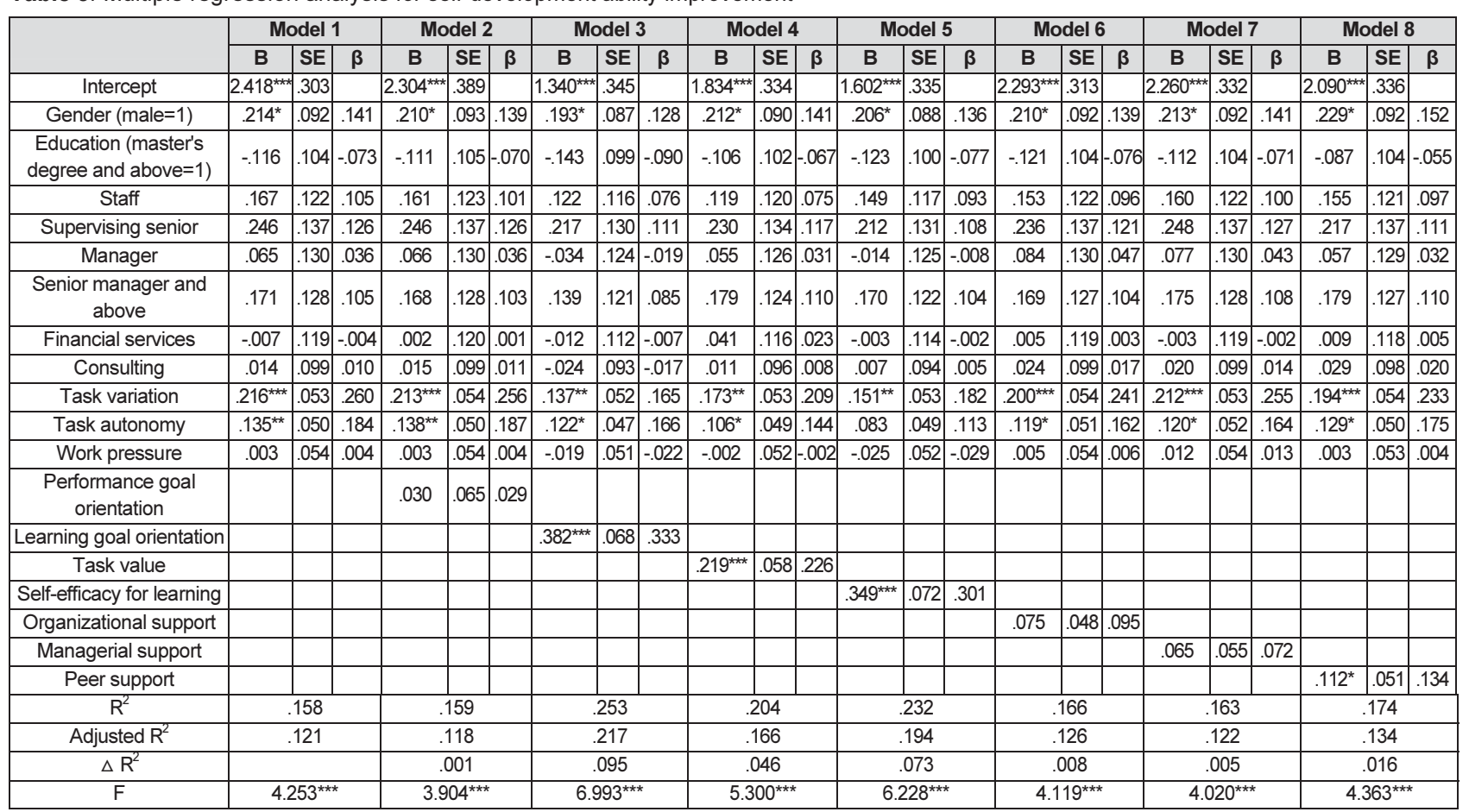

${ }^{*} p<.05,{ }^{* *} p<.01,{ }^{* * *} p<.001$

B: unstandardized coefficient, SE: standard error, $\beta$ : standardized coefficient 


\section{Discussion and Conclusion}

This study empirically investigated the effects of learning motivation, job characteristics and supportive learning environment on the informal learning of professionals working in large accounting firms in Korea. The discussions and conclusions for the results of the study are as follows.

First, peer-support of the supportive learning environment was the most influential factor in acquiring knowledge and skills related to job performance through informal learning. It was not revealed in the previous research that peer support was the most important for accounting firm professionals along with learning motivation factors for acquiring work related knowledge and skills. In addition, task value of learning motivation was the next most important factor and learning goal orientation was also an important learning motivation factor after task value. The positive effects in learning motivation were partially supported by Moon and $\mathrm{Na}$ (2011). However, it was noteworthy that the influence of task value was the largest among all the other learning motivation factors covered in this study. The results of this study shows that professionals participate more actively in learning and acquire new knowledge when it is related to their work.

Second, all learning motivation factors except for performance goal orientation, all factors of supportive learning environment and task autonomy of job characteristics were found to be effective in adapting to organization and understanding context through informal learning. Among these factors, task autonomy and organizational support were the most important. The fact that task autonomy, which is considered to be very important in the performance of professionals (Ritzer \& Walczak, 1988; Pavalko, 1988), can be also very important in adapting to organization and understanding context, emphasizes the need to guarantee the task autonomy of professionals working in accounting firms. The results of the study, which showed that the organizational support in the supportive learning environment was particularly strong, are in line with the precedent study of Skule (2004) which found that informal learning is more likely to occur under learning supportive organizational culture with the high level of support from the management. These results suggest that institutional support of the organization should be provided rather than relational support in order to promote informal learning of accounting professionals.

Third, all learning motivation except performance goal orientation, all supportive learning environments and task autonomy were found to be effective factors to learn how to collaborate with other people inside and outside of the organization through informal learning. Amongst them, peersupport was found to have the greatest influence. Peer- support provides comprehensive support for emotional and business aspects as well as practical knowledge and information about work (Baruch-Feldman et al., 2002). Such peer-support was the most important factor in acquiring work-related knowledge and skills, as well as in the formation of relationships in this study.

Fourth, in improving self-development ability, learning motivation factors except for performance goal orientation, task variation, task autonomy among job characteristics and peer-support of supportive learning environment were found to be the positive factors. In particular, learning goal orientation was the most important factor and self-efficacy for learning was the next most important factor in improving self-development-ability. Previously, Kremer (2006)'s study of law firm employees also found that learning orientation and growth were the most important factor in informal learning. Task variation was found to be more effective than task autonomy. This supports a previous study that informal learning was reinforced by higher task variations that gave new and challenging tasks to organizational members (Doornbos et al., 2008). Ellström (2001) also argued that job-related characteristics such as diversity and complexity of tasks, serve to facilitate learning within the organization. This study also found that peer support to be a positive factor in improving self-development-ability of accounting professionals, although it has the lowest impact among other effective factors.

In summary, it was found that learning motivation, job characteristics, and supportive learning environment should be considered important to promote informal learning for professionals who are working for accounting firms. This study further elaborated more specifically which factors could be particularly more important for each informal learning outcome. Learning goal orientation and task value of learning motivation had a relatively high level of impact on informal learning, whereas performance goal orientation may not be as important. This suggests that the desire for learning and the importance and usefulness of learning contents were more important than the motivation to gain recognition from others in order to facilitate informal learning of professionals at accounting firms.

In addition, the study found that an organizational supportive learning environment can be important to promote informal learning. It also confirmed that peersupport was more important than organizational support and managerial support in task-related knowledge acquisition and relationship formation. Peer-support was a concept that covers all the support received from colleagues, includes emotional and business aspects. Organizational members often interact with colleagues in their day-to-day work to acquire the knowledge and methods necessary for their tasks or to share their experiences with each other in order 
to solve problems. This tendency can be found from learning new tasks and increase the level of human network formation within and outside the organization. However, institutional support rather than relational support such as peer-support was found to be a more important factor to improve the understanding of the context of the organization's vision and strategy. Therefore, in order to facilitate informal learning, it is necessary to consider not only relational support but also strategic support for system such as planning, evaluation and compensation to improve learning and performance.

As the importance of informal learning in the workplace is getting higher, many studies on informal learning have been continued. However, workplace learning studies for professionals were very poor. Therefore, this study has academic significance in that it has identified specific factors that are relatively more important by considering individual, job and organizational factors as the leading factors affecting informal learning of professional. Nevertheless, there were a few limitations in this study. The following are suggestions for the developmental follow-up studies to overcome the limitations.

First, this study was conducted only on professionals who worked in Big four accounting firms in Korea. The accounting firms can be considered the major representative of accounting firms in Korea; but there will be limitations to extend and apply the results to professionals in other fields. Subsequent studies involving professionals in various fields need to be conducted.

Second, it is necessary to measure and analyze the informal learning separately for learning process and outcomes. This study measured and analyzed informal learning outcomes to the extent that they have achieved the purpose of informal learning, so it was not possible to look at how learning motivation, job characteristics, and supportive learning environment have led to learning outcomes. More specifically, it is necessary to examine the learning process as well as the outcomes to establish informal learning strategies.

\section{References}

Ahmed, U., Majid, A. H. A., \& Zin, M. M. (2016). Moderation of meaningful work on the relationship of supervisor support and coworker support with work engagement. The East Asian Journal of Business Management, 6(3), 15-20.

Bandura, A. (1991). Social cognitive theory of moral thought and action. Handbook of Moral Behavior and Development, 1, 45-103.
Billett, S. (2000). Guided learning at work. Journal of Workplace Learning, 12(7), 272-285.

Boud, D., \& Middleton, H. (2003). Learning from others at work: communities of practice and informal learning. Journal of Workplace Learning, 15(5), 194202.

Baruch-Feldman, C., Brondolo, E., Ben-Dayan, D., \& Schwartz, J. (2002). Sources of social support and burnout, job satisfaction, and productivity. Journal of Occupational Health Psychology, 7(1), 84.

Button, S. B., Mathieu, J. E., \& Zajac, D. M. (1996). Goal orientation in organizational research: A conceptual and empirical foundation. Organizational Behavior and Human Decision Processes, 67(1), 26-48.

Cheetham, G., \& Chivers, G. (2001). How professionals learn in practice: an investigation of informal learning amongst people working in professions. Journal of European Industrial Training, 25(5), 247-292.

Choi, W., \& Jacobs, R. L. (2011). Influences of formal learning, personal learning orientation, and supportive learning environment on informal learning. Human Resource Development Quarterly, 22(3), 239-257.

Doornbos, A. J., Simons, R. J., \& Denessen, E. (2008). Relations between characteristics of workplace practices and types of informal work-related learning: A survey study among Dutch Police. Human Resource Development Quarterly, 19(2), 129-151.

Ellinger, A. D. (2005). Contextual factors influencing informal learning in a workplace setting: The case of "reinventing itself company". Human Resource Development Quarterly, 16(3), 389-415.

Ellström, P. E. (2001). Integrating learning and work: Problems and prospects. Human Resource Development Quarterly, 12(4), 421-435.

Enos, M. D., Kehrhahn, M. T., \& Bell, A. (2003). Informal learning and the transfer of learning: How managers develop proficiency. Human Resource Development Quarterly, 14(4), 369-387.

Eraut, M. (2004). Informal learning in the workplace. Studies in Continuing Education, 26(2), 247-273.

Feldman, D. C. (1981). The multiple socialization of organization members. Academy of Management Review, 6(2), 309-318.

Financial Supervisory Service. (2012). Quality Control Manual for Accounting Firms.

Freidson, E. (2001). Professionalism, the Third Logic: on the Practice of Knowledge. University of Chicago press.

Hackman, J. R., \& Oldham, G. R. (1976). Motivation through the design of work: Test of a theory. Organizational Behavior and Human Performance, 16(2), 250-279. 
Hojabri, R., Eftekhar, F., Sharifi, M., \& Hatamian, A. (2014). Knowledge management in an Iranian health organization: Investigation of critical success factors. The International Journal of Industrial Distribution \& Business, 5(4), 31-42.

Holton, E. F., Bates, R. A., Seyler, D. L., \& Carvalho, M. B. (1997). Toward construct validation of a transfer climate instrument. Human Resource Development Quarterly, 8(2), 95-113.

Kang, M. J., \& Hwang, H. J. (2014). The effect of employees' perception of a supervisor's servant leadership on employees' perceived organization's support: the mediating effect of employees' perceived supervisor's supports. Journal of Distribution Science, 12(3), 105-109.

Kang, Y. J. (2005). An empirical study on affecting factors of learning and transfers performance of police officers. Korea Public Administration Journal. 14(2), 159-197.

Korea Employment Information Service. (2016). Tomorrow's world of work.

Kremer, A. L. (2006). Predictors of participation in formal and informal workplace learning: Demographic, situational, motivational and deterrent factors. Doctoral dissertation, George Mason University.

Kwakman, K. (2003). Factors affecting teachers' participation in professional learning activities. Teaching and Teacher Education, 19(2), 149-170.

Lindsay, H. (2016). More than 'continuing professional development': A proposed new learning framework for professional accountants. Accounting Education, 25(1), 1-13.

Lohman, M. C. (2005). A survey of factors influencing the engagement of two professional groups in informal workplace learning activities. Human Resource Development Quarterly, 16(4), 501-527.

Marsick, V. J. (2009). Toward a unifying framework to support informal learning theory, research and practice. Journal of Workplace Learning, 21(4), 265275.

Marsick, V. J., \& Watkins, K. E. (2001). Informal and incidental learning. New Directions for Adult and Continuing Education, 2001(89), 25-34.

Moon, S. Y., \& Na, S. I. (2011). Variables associated with informal learning of workers in small and mediumsized enterprises. Andragogy Today: International Journal of Adult \& Continuing Education, 14(3), 111138.

Parveen, M., Ullah, O., Salam, M., \& Zakir, N. (2014). Impact of teachers' professional development on students' performance. The International Journal of Industrial Distribution \& Business, 5(3), 15-24.
Pavalko, R. M. (1988). Sociology of occupations and professions (2nd ed.). lataka, IL: FE Peacock Pub.

Pintrich, P. R., \& De Groot, E. V. (1990). Motivational and self-regulated learning components of classroom academic performance. Journal of Educational Psychology, 82(1), 33.

Pintrich, P. R., Smith, D. A., Garcia, T., \& McKeachie, W. J. (1993). Reliability and predictive validity of the motivated strategies for learning questionnaire (MSLQ). Educational and Psychological Measurement, 53(3), 801-813.

Ritzer, G., \& Walczak, D. (1988). Rationalization and the deprofessionalization of physicians. Social Forces, 67(1), 1-22.

Rowden, R. W. (2002). The relationship between workplace learning and job satisfaction in US small to midsize businesses. Human Resource Development Quarterly, 13(4), 407-425.

Sambrook, S., \& Stewart, J. (2000). Factors influencing learning in European learning orientation organizations: Issues for management. Journal of European Industrial Training, 24(2/3/4), 209-219.

Schön, D. A. (1983). The Reflective Practitioner: How Professionals Thinkiln Action. New York: Basic Books.

Schunk, D. H., Meece, J. R., \& Pintrich, P. R. (2012). Motivation in Education: Theory, Research, and Applications (3rd ed.). Harlow: Pearson Higher Ed.

Skule, S. (2004). Learning conditions at work: a framework to understand and assess informal learning in the workplace. International Journal of Training and Development, 8(1), 8-20.

Tracey, J. B., Tannenbaum, S. I., \& Kavanagh, M. J. (1995). Applying trained skills on the job: The importance of the work environment. Journal of Applied Psychology, 80(2), 239.

Tracey, B., \& Tews, M. J. (2005). Construct validity of a general training climate scale. Organizational Research Methods, 8(4), 353-374.

Vallerand, R. J., Pelletier, L. G., Blais, M. R., Briere, N. M., Senecal, C., \& Vallieres, E. F. (1992). The academic motivation scale: a measure of intrinsic, extrinsic, and amotivation in education. Educational and Psychological Measurement, 52(4), 1003-1017.

Venkatesh, B., \& Sharma, A. K. (2015). Interactive motivational concept: a study of motivation among corporate of Bhopal region in India. The Journal of Asian Finance, Economics and Business, 2(2), 3538.

Webster-Wright, A. (2009). Reframing professional development through understanding authentic 
professional learning. Review of Educational Research, 79(2), 702-739.

Woods, D., \& Marsden, H. (2009). How professionals learn. Training Journal, 42-46.

Zahm, K. W., Veach, P. M., Martyr, M. A., \& Leroy, B. S. (2016). From novice to seasoned practitioner: A qualitative investigation of genetic counselor professional development. Journal of Genetic Counseling, 25(4), 818-834.

Zusho, A., Pintrich, P. R., \& Coppola, B. (2003). Skill and will: The role of motivation and cognition in the learning of college chemistry. International Journal of Science Education, 25(9), 1081-1094. 